\title{
Endometriosis and endometriosis-associated cancers: new insights into the molecular mechanisms of ovarian cancer development
}

\author{
Amy Dawson', Marta Llauradó Fernandez¹, Michael Anglesio ${ }^{1,2}$, Paul J Yong1 ${ }^{1}$, and Mark S Carey ${ }^{1,3}$ \\ ${ }^{1}$ Department of Obstetrics \& Gynaecology, Faculty of Medicine, University of British Columbia, Vancouver, British Columbia V6Z 2K8, Canada \\ 2Department of Pathology and Laboratory Medicine, Faculty of Medicine, University of British Columbia, Vancouver, British Columbia V6T 2B5, Canada \\ ${ }^{3}$ Department of Surgical Oncology, BC Cancer Agency, Vancouver, British Columbia V5Z 1G1, Canada
}

Correspondence to: MS Carey. Email: mark.carey@ubc.ca

\begin{abstract}
Endometriosis is a fascinating disease that we strive to better understand. Molecular techniques are shedding new light on many important aspects of this disease: from pathogenesis to the recognition of distinct disease variants like deep infiltrating endometriosis. The observation that endometriosis is a cancer precursor has now been strengthened with the knowledge that mutations that are present in endometriosis-associated cancers can be found in adjacent endometriosis lesions. Recent genomic studies, placed in context, suggest that deep infiltrating endometriosis may represent a benign neoplasm that invades locally but rarely metastasises. Further research will help elucidate distinct aberrations which result in this phenotype. With respect to identifying those patients who may be at risk of developing endometriosis-associated cancers, a combination of molecular, pathological, and inheritance markers may define a high-risk group that might benefit from risk-reducing strategies.
\end{abstract}

Keywords: endometriosis, ovarian cancer, molecular mechanisms, biomarkers

Published: 25/01/2018

Received: 03/08/2017

ecancer 2018, 12:803 https://doi.org/10.3332/ecancer.2018.803

Copyright: (c) the authors; licensee ecancermedicalscience. This is an Open Access article distributed under the terms of the Creative Commons Attribution License (http://creativecommons.org/licenses/by/3.0), which permits unrestricted use, distribution, and reproduction in any medium, provided the original work is properly cited. 


\section{Introduction}

Endometriosis is a common and complex disease, affecting approximately $6-10 \%$ of women of reproductive age. The disease has a significant impact on women, as it is prevalent in greater than one-third of women with infertility and two-thirds of women with chronic pelvic pain [1]. Endometriosis is defined by the presence of ectopic endometrium (including glands and stroma) in extrauterine locations such as the rectovaginal septum, peritoneal surfaces, or ovaries [2]. The disease varies considerably in its presentation and severity. Patients experience a wide range of symptoms from asymptomatic disease to significant dyspareunia, dysmenorrhea, and infertility [3]. Interestingly, symptom severity does not necessarily correlate with the clinical extent of disease, and disease progression can be highly unpredictable. These gynaecologic disorders rarely cause mortality; however, they may have a significant impact on a patient's quality of life, and some cases may represent risk factors for gynaecologic malignancies such as cancer.

While practicing physicians are very familiar with the clinical features of endometriosis, emerging molecular technologies are enhancing our understanding of the disease in order to improve knowledge and treatment management. The purpose of this review paper is to discuss some of the recent progress that has been made as a result of the study of the molecular biology of endometriosis. Some of the key questions relating to the etiology, progression, and malignant transformation of endometriosis are now being clarified. In this review, we provide some interesting perspectives on this emerging information.

\section{Risk factors and etiology of endometriosis}

Significant risk factors for the development of endometriosis include conditions that increase the chances of retrograde menstruation and genetic/hereditary factors. Risk factors for endometriosis include early menarche, nulliparity, dysfunctional uterine bleeding, aberrant estrogen levels [4-7], and low body mass index [5]. Factors such as adequate exercise may be preventative against development of endometriosis [8]. It is known that the incidence of endometriosis in women with first-degree relatives who also have the disease may be up to ten times higher than that of the general population $[9,10]$. There is likely to be a multifactorial genetic predisposition for endometriosis, and genome-wide association studies (GWAS) have indicated single-nucleotide polymorphism (SNP) profiles which may increase the risk of endometriosis in individuals [11]. In 2012, Nyholt et al [12] identified 18 genomic regions harboring 38 putative endometriosis-associated SNPs in a GWAS involving 4,604 cases of endometriosis. Among the significant aberrations identified were SNPs associated with the WNT4 gene, known to be critical in reproductive tract differentiation and development in mammalian females [13, 14] as well as steroidigenesis [15], VEZT, shown to be downregulated in gastric cancers [16], and GREB1, an estrogen-regulated gene shown to be important in several hormone-responsive cancers [17, 18]. Another GWAS on 2,109 cases of endometriosis in 2013 performed by Albertsen et al also showed that SNPs associated with WNT4 were associated with the development of endometriosis [19], confirming results previously seen by Uno et al in 2010 [20] and Painter et al in 2011 [21]. A recent GWAS meta-analysis by Uimari et al in 2017 indicated certain cellular control pathways which were enriched in endometriosis; MAPK-related pathways controlling cell survival, migration, division, and gene expression, as well pathways involved in extracellular matrix structure [22]. Also in 2017, Sapkota et al identified five novel loci in sex steroid hormone pathways associated with endometriosis risk (FN1, CCDC170, ESR1, SYNE1 and FSHB) [23]. While GWAS data can provide an insight into genomic aberrations that predispose to endometriosis, further genetic and functional investigation is necessary in order to fully understand the underlying mechanisms responsible for the disease phenotype [24].

There are several theories pertaining to the origin of endometriotic lesions. Ectopic implants of endometrial tissue may arise by retrograde menstruation (the reflux of endometrial tissue into the peritoneal cavity), resulting in the implantation and proliferation endometrial glands and stroma on extrauterine surfaces [25]. An alternate theory of coelomic metaplasia focuses on the de novo formation of endometrial glands and stroma by abnormal tissue differentiation from non-endometrial tissues [26]. Other common theories of origin suggest a lymphatic or haematogenous spread of endometrial tissue by dissemination through endothelial channels [27]. Based on recent molecular studies, it is interesting to speculate on the origins of endometriosis. Although there may be more than one possible explanation, current evidence supports the theory that endometriosis arises from the establishment, proliferation, and differentiation of a stem cell [28], or the implantation of endometrial cells secondary to retrograde menstruation. Stem cells can be extracted from menstrual blood and these cells show both mesenchymal and embryonic cell markers [29]. Presumably these stem cells have the capacity to give rise to both cell types (endometrial glands and stroma). Alternatively, retrograde menstruation and implantation of both endometrial glandular and stromal cells could give rise to endometriosis. Figure 1 (1A and $1 \mathrm{~B})$ shows an example of both glands and stroma in a typical endometriosis lesion. 
In a recent study of deep infiltrating endometriosis, mutations found in glandular epithelium were not found in surrounding stroma in both of the two cases analysed [30]. This suggests that the stroma could result from metaplastic change induced by the glandular epithelium. It is of interest in the development of patient-derived xenografts that the stromal tumour component is induced and derived from the mouse tissues [31, 32]. Eutopic endometrial cells with significant changes in their transcriptomes have been reported in women with endometriosis compared to women without endometriosis, indicating abnormalities that may predispose endometrial tissue to implant in extrauterine locations [33].

Interestingly, Barrett's oesophagus is a disease that has been extensively studied and shares a number of important features with endometriosis, including an increased risk of cancer [34]. Barrett's oesophagus was traditionally thought to result from the metaplastic transformation of squamous epithelium. Inflammation and cell injury from acid reflux results in the formation of glandular epithelium replacing the normal stratified squamous epithelium. Evidence now suggests that the ongoing inflammation imposes selection pressure for mucin-producing cells and that these cells can better resist the acidic environment [35]. Further research by a number of investigators suggests that the cell of origin may in fact reside in the submucosal glands of the oesophagus supporting the theory that transdifferentiation (metaplastic change) of the basal squamous cells may not give rise to the columnar epithelium [36-38]. This information provides little support for the theory that endometriosis is a metaplastic change of either peritoneum or embryonic rest cells, particularly when the differentiation of a single cell must result in two different cell types [39]. Knowing that deep-infiltrating endometriosis lesions display a unique somatic mutation signature and that distinct lesions have demonstrated clonal relatedness [30], we postulate that cases of extra-peritoneal endometriosis seem even less likely to have arisen from metaplastic changes and instead are likely the result of lymphatic or haematogenous spread. Further functional analyses are required to better understand the origin and establishment of endometriosis lesions.

\section{Endometriosis as a cancer precursor: the historical perspective}

A number of gynaecologic cancers of specific histotypes are thought to originate from endometriosis. In 1927, Sampson first published a report of a malignancy associated with endometriosis wherein he described specific criteria for endometriosis-associated ovarian cancers (EAOCs) [27]. First, there must be a clear example of endometriosis in association or close proximity to the cancer. In addition, no other primary tumour site must exist and the histology of the tumour must be consistent with an endometrial origin. Endometriosis is frequently described in association with clear cell and endometrioid ovarian cancers. A study by Vercellini et al in 1993 had showed a 26.3\% history of endometriosis in women with endometrioid ovarian cancers (EnOC), $21.1 \%$ in clear cell ovarian cancers (CCC) [40]. The occurrence of synchronous endometriosis in ovarian cancer lesions was shown to be $40.6 \%$ in CCC, and $23.1 \%$ in EnOC in 1997 [41]. In a large Canadian database of ovarian cancers, endometriosis was identified in the final pathology reports in $51 \%$ of CCC and $43 \%$ of EnOC [42].

In 1953, RB Scott amended Sampson's original criteria, to add an additional criterion stating that the endometriosis associated with cancers must show a morphologic progression from benign to malignant in a contiguous fashion. This transformation was further characterised by LaGrenade and Silverberg in 1988 who described what appeared to be a premalignant precursor, so-called atypical ovarian endometriosis [see Figure $1(2 \mathrm{~A})$ ] [43]. Atypical endometriosis [AE, see Figure 1 (2A and 2B)] may be seen relatively frequently associated with endometriosis-associated cancers. Reported rates of AE vary from $20 \%$ to $80 \%$ depending on the series [42-44]. Reasons for such variation in reported rates is that there is a lack of agreement on pathological criteria for the diagnosis of $A E$, and the diagnosis is uncommon, noted in only about 2-3\% of endometriomas [45]. Stamp et al found that with more careful pathology review on archived formalin fixed paraffinembedded tissue sections, the diagnosis of $\mathrm{AE}$ was made twice as frequently on pathology review compared to the final diagnosis on the original reports. Moreover, these same authors searched the pathology records of a large tertiary hospital database spanning 15 years, and only 8 cases of AE were found in ovarian endometriomas without an associated cancer [42].

While endometriosis is a common disease, the overall risk of an endometriosis-associated cancer remains low. In a large epidemiological study, the overall frequency of ovarian cancer arising in a patient with a diagnosis of endometriosis was $0.3-0.8 \%$, a risk that was $2-3$ times higher than controls [46]. Interestingly, these epidemiological studies show an association with specific histological subtypes of ovarian cancer. This information supports the historical pathological observations that clear cell ovarian and endometrioid ovarian carcinomas may arise from endometriosis. Other neoplasms such as seromucinous borderline [47, 48], low-grade serous ovarian carcinomas [49], adenosarcomas [50, 51] and endometrial stromal sarcomas [52] may also arise from endometriosis [49, 53-55]. CCC and EnOC together represent the second and third most common epithelial ovarian cancers (approximately $20 \%$ of all cases) [56] and the only subtypes wherein a direct clonal relationship between endometriosis, as a direct precursor, and the cancer has been made [54, 57]. Better understanding of the precursor lesions which lead to these cancer types will improve their prevention and diagnosis. 


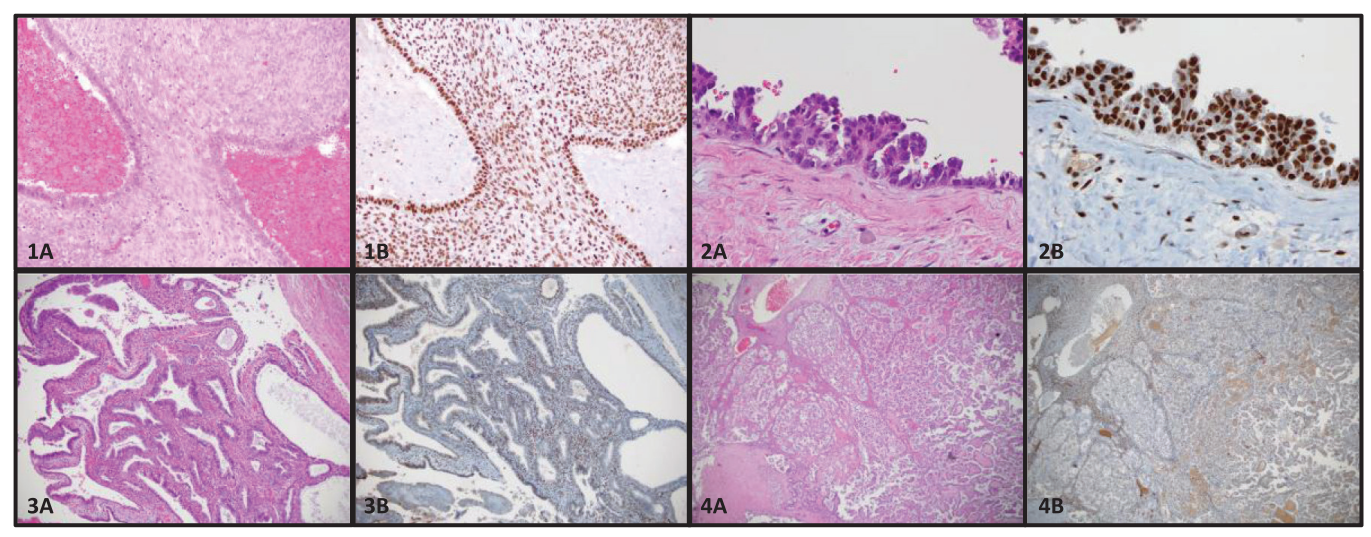

Figure 1. Photomicrographs of endometriosis and EAOC stained by hematoxylin and eosin (A) or immunohistochemistry for BAF250a (B). 1) Typical endometriosis lesion (1A) maintaining BAF250a expression (1B). 2) Atypical endometriosis lesion (2A) demonstrating cellular hyperplasia maintaining BAF250a expression (2B). 3) Endometrioid ovarian carcinoma (3A) with BAF250a loss (3B). 4) Clear cell ovarian carcinoma (4A) with BAF250a loss (4B).

\section{Disease characteristics and clinical overview}

The clinical diagnosis of endometriosis is challenging, as signs and symptoms may vary considerably and there is a lack of reliable diagnostic serum biomarkers [58]. Elevated levels of the biomarker CA-125 are not specific since they can indicate the presence of various gynaecologic pathologies, such as endometriosis, ovarian cancers or inflammation [59]. In some cases, levels of the serum biomarker HE4 can be used to distinguish endometriosis from ovarian and endometrial cancers [60]. In many patients, endometriosis is clinically suspected based on history and examination, and treated empirically with hormonal therapy (e.g., estrogen-progestin contraceptives or progestin-only therapies) without surgery [61]. A reliable diagnostic serum biomarker would represent a major advance for clinically diagnosing endometriosis [58].

Surgery with histological confirmation of ectopic endometrial glands and stroma remains [see Figure $1(1 \mathrm{~A})$ ] the gold standard for diagnosis $[62,63]$. Surgery is generally reserved for patients who fail medical therapy, or who desire pregnancy, and is usually performed by laparoscopy [64-68]. Gonadotropin-releasing hormone agonists are also used in severe cases. Other potential treatment options include hormone receptor (estrogen or progesterone) modulators, immune modulators, aromatase inhibitors, and anti-angiogenic drugs [69-71]. There are a number of excellent clinical reviews published on endometriosis. These manuscripts offer very comprehensive discussions of the clinical features of endometriosis and its treatment, and are therefore not further discussed in this review [64, 69, 72, 73].

There are three subtypes of endometriosis described in patients that can be clinically identified: ovarian endometriosis (endometriomas), superficial peritoneal endometriosis, and deep infiltrating endometriosis. Endometriotic lesions have been shown to have altered estrogen biosynthesis and are estrogen dependent. Estrogen dysregulation appears to be linked to increased aromatase expression and activity [74]. Additionally, resistance to the anti-proliferative effects of progesterone is associated with a shift in estrogen receptor isoform expression resulting in estrogen-mediated inhibition of progesterone receptor expression [75]. Furthermore, epigenetic alterations related to alterations in hormonal signaling pathways have also been reported [76]. In addition to imbalances in hormone regulation, oxidative stress caused by high iron levels has been reported to lead to increased levels of somatic mutations $[77,78]$. Vercellini's 'incessant menstruation hypothesis' [79] cites retrograde transport of blood, endometrial tissue, and carcinogens as potentially leading to the genesis of both endometriosis, as well as serous, endometrioid, and clear cell ovarian cancers. High levels of oxidative stress and iron exposure are the consequence of the inflammatory response that may arise from either retrograde menstruation or the endometriosis itself. Oxidative stress leads to increased angiogenesis, endometriosis proliferation, and selective iron-mediated DNA damage leading to potential oncogene mutations [80]. Local and systemic inflammatory responses likely play a key role in the cause of chronic pain and infertility [81-85]. Thus, inflammatory responses, along with the known hormonal dysregulation in endometriotic implants, may drive carcinogenesis [86]. While some EAOCs arise with obviously associated endometriosis, this is not always the case. Interestingly, many EAOC lack identifiable endometriotic precursor lesions as they may be destroyed by the resulting EAOC or simply not detected due to sampling limitations. We suspect, based on the frequency of adhesion formation in cases of EAOC, that the incidence of pre-existing endometriosis in such cases is very high. 


\section{Development of EAOC from endometriosis}

The concept that endometriosis is the precursor lesion of some ovarian cancer subtypes has been supported by a number of lines of investigation. Initially as mentioned above, the association was noted by pathological methods, though epidemiological, and genetic studies have been valuable [25, 27, 40, 43, 44, 49, 87-92]. Jiang et al described some of the first studies suggesting a molecular basis linking endometriosis with cancer development in 1998. They demonstrated the same loss of heterozygosity (LOH) events in endometriosis lesions and adjacent endometrioid ovarian cancers in $82 \%$ of cases examined $(n=11)$ [87]. Similar evidence was reported by Prowse et al in 2006 , who demonstrated common LOH events in both endometrioid and clear cell OCs and their associated endometriosis lesions, including both adjacent and contralateral endometriosis [90]. Additionally, LOH resulting in PTEN loss may be an early driver event in the genesis of in EAOC from endometriosis $[93,94]$. Over the last 7 years, sequencing and immunohistochemical studies have provided confirmatory evidence that mutations found in endometriosis-associated cancers are found in adjacent endometriosis. These sequencing studies clearly demonstrate a clonal relationship between benign and malignant counterparts confirming that the cancers have fact arisen from the endometriotic lesions [42, 54, 57, 95].

Somatic mutations and other genomic aberrations are found in endometriosis that have been implicated in the development of cancer. Mutations in TP53 [96, 97] KRAS [30, 98], PTEN [94], PIK3CA [99, 100], and ARID1A gene regions [54, 57] have been described. Loss of expression of mismatch repair enzymes [101], microsatellite instability [102], and tissue-specific gene copy-number changes [103, 104], may also be seen in endometriosis lesions. LOH in endometriosis at known oncogenic loci is also frequently seen [94, 105-110]. SNPs that are associated with oncogenic transformation (seen in GWAS datasets) have been identified in cases of endometriosis [12, 19-21].

A high degree of inflammation, like that which is found in endometriosis, is a risk factor for the development of other cancers, similar to what is seen in some cases of Barrett's oesophagus [111]. Dysregulation of gene expression in the complement pathway has been shown in endometriosis compared to normal tissues by Surwanyashi et al in 2014. The same authors also demonstrated linkages between upregulation of the complement pathway and upregulation of KRAS and PTEN-regulated pathways, both frequently involved in oncogenesis and maintenance of the cancer phenotype in vitro [112]. The complement pathway has been linked with supporting tumour growth through various mechanisms [113]. In 2015, Edwards et al demonstrated that $85 \%$ of atypical endometriosis lesions demonstrated a cancer-like immunological gene signature, compared to $30 \%$ of typical endometriosis lesions [114]. In 2015, a meta-analysis reported by Lee et al including over 15,000 ovarian cancer patients, evaluated the 38 putative endometriosis-associated SNPs identified by Nyholt in 2012 [12]. Eight of these were associated with significant risk for ovarian cancer (rs7515106, rs7521902, rs742356, rs4858692, rs1603995, rs4241991, rs6907340, and rs10777670) [115]. Also in 2015, Lu et al demonstrated shared genetic risk between endometriosis and epithelial ovarian cancer, particularly clear-cell and endometrioid histotypes using genome wide association (GWAS) datasets [89].

$A R I D 1 A$ is a tumour suppressor gene that was found to be mutated in a considerable number of EAOC [57]. Investigators were initially very excited to find that up to $42-61 \%$ of CCC and 21-33\% EnOC show loss of the corresponding ARID1A gene protein expression (BAF250a) on IHC [see Figure 1 (3B)] [42, 57, 116]. ARID1A regulates important cellular functions (proliferation and genomic stability) as a tumour suppressor gene; therefore, it was thought that it might play a role in the transformation of endometriosis to cancer [117]. In 2015, Anglesio et al demonstrated that clear-cell ovarian carcinomas shared many mutations with associated concurrent endometriosis lesions, including mutations in ARID1A. Shared mutations in PIK3CA were also detected between endometriosis and clear-cell lesions, an event occurring in early progression mechanisms in other cancer types [54]. This study clearly demonstrated described mutations in contiguous endometriosis shared by EAOC, and even some distant lesions contained the same (PIK3CA and ARID1A) mutations. Studies examining BAF250a expression by IHC show that in just over half of the reported cases of EAOC, loss of BAF250a expression is seen the majority of the time (67-80\%) in areas of contiguous endometriosis or atypical endometriosis (see Figure 1), and that a loss of Baf250a protein expression seemed to be an early molecular event in the development of Baf250a-negative EAOC [42, 95, 118]. Interestingly, ARID1A mutations are not sufficient on their own to cause cancer [119]. In support of this observation, Borrelli et al described partial loss of BAF250a in normal endometrium in the absence of cancer [120]. An important study recently reported that that $65 \%$ of cancer-causing genomic aberrations are random DNA repair abnormalities [121]. Taking this information into context, one can conclude that BAF250a loss in endometriosis could represent an EAOC precursor lesion; however, ARID1A mutations are neither a necessary driver mutation nor a significant determinant of the malignant phenotype. The presence of mutations in endometriosis is a sign of broader genomic disruption leading to the development of EAOC. Figure 2 shows a schematic of the establishment and evolution of endometriosis lesions to EAOC. Studies have been done comparing patient outcomes in EAOC based on the presence or absence of BAF250a expression. Based on the available evidence, it has yet to be determined as to whether there are differences in prognosis or treatment outcomes related to BAF250a loss in EAOC [122, 123]. There are few identifiable proteomic changes in a panel of proteins evaluated by reverse phase protein array (RPPA) suggesting that BAF250a loss does not define a specific proteomic signature [124]. Additionally, the presence or absence of an endometriosis precursor lesion in EAOC has not been associated with a change in overall disease outcome [125]. 


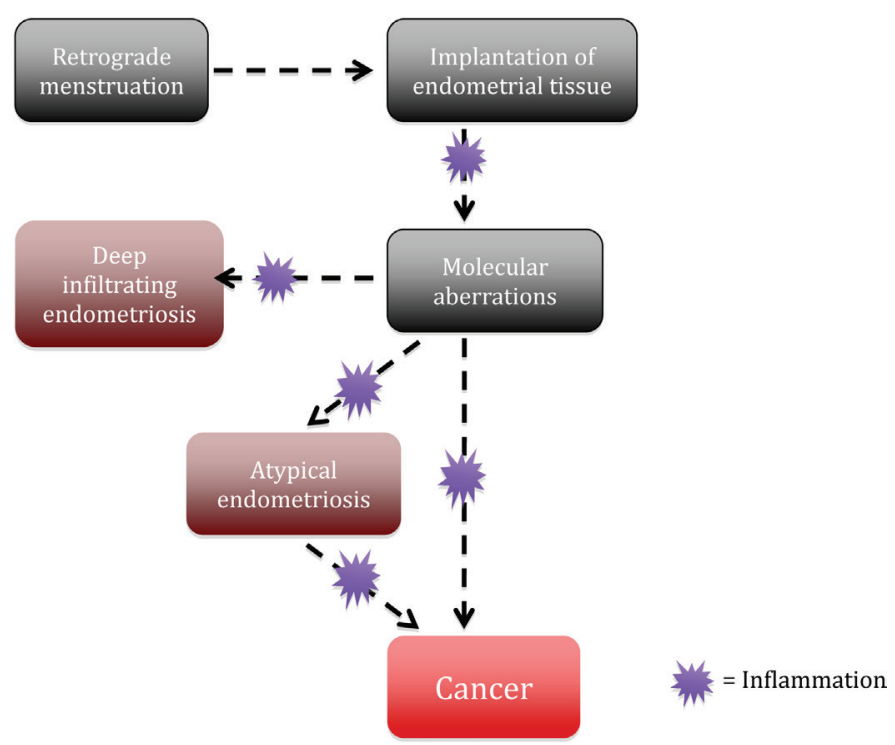

Figure 2. Potential process of the establishment and evolution of endometriosis lesions to EAOCs.

\section{Endometriosis as a neoplasm}

Deep infiltrating endometriosis is an interesting rare subtype of endometriosis which was recently subjected to genomic evaluation. Deep endometriosis has a propensity to locally invade surrounding structures (bowel, bladder, ureter) but rarely metastasises. Anglesio et al demonstrated the presence of somatic mutation events in $79 \%$ of 24 cases, with $26 \%$ of all cases screened harbouring statistically significant somatic mutations in known cancer driver genes such as KRAS, PIK3CA, ARID1A, and PPP2R1A. In the analysis of a smaller subset of samples, mutations in KRAS found to be present in the epithelial component of endometriosis lesions were absent in the stroma. Additionally, one patient was found to have the same KRAS mutation in three spatially distinct endometriosis lesions. While these molecular events are commonly found in EAOCs, this study demonstrated their presence in deep infiltrating endometriosis. While traditionally oncogenic driver mutations (like KRAS) were present in a quarter of samples, they did not appear to indicate the likelihood of the lesion to progress into a gynaecologic cancer nor appear to be required for the development of the deep-infiltrating lesions. This suggests that additional or different molecular mechanisms may be at play in the development of endometriosis, and future research using a broad array of molecular technologies (epigenetic, splicing aberrations, complex chromosomal rearrangements, transcriptome, proteome and post-translational changes) to investigate the functional biology of endometriosis is warranted. Novel molecular technologies may also help explain the biology of clonally identical lesions in the same patient. Finally, the unusual presence of endometriosis in lymph nodes has been described, with some cases showing BAF250a loss [120]. Thus, one might expect that these very unusual cases are molecularly distinct as they mimic locally metastatic cancers. Perhaps even the deep-infiltrating subtype of endometriosis, which demonstrates unequivocal invasion of surrounding tissues, may be more appropriately considered a neoplasm than a benign condition. Better understanding of the molecular pathology of this disease may provide useful strategies to diagnose and treat complex cases, with the goal of reducing morbidity and disease complications like infertility.

\section{Prevention strategies for EAOCs}

Endometriosis is highly prevalent in women of reproductive age, causing dysmenorrhea, chronic pelvic pain, infertility and in some instances even cancer. With our rapidly advancing knowledge of neoplastic diseases and modern technologies, the application of molecular science will hopefully provide us with an opportunity to identify the etiology of endometriosis, and the patients with endometriosis who are at risk 
of developing cancer. In order to separate patients at risk of EAOC from those who will continue to have benign disease, the application of highly sensitive and specific novel molecular biomarkers should be explored. Likely a combination of epidemiological, pathological and molecular risk stratification will be required. The finding of atypical endometriosis in the absence of cancer is rare and the risk of developing cancer in such cases is unknown. Pearce et al [53] showed that women with a history of endometriosis in higher-risk genetic groups had up to a 4-9\% lifetime risk of developing ovarian cancer after statistical adjustment for oral contraceptive use and parity. This high-risk group represented $1.8 \%$ of the total study population of over 5,000 women with ovarian cancer. This type of risk stratification could serve to identify a baseline population for further follow-up and molecular testing.

Additional research should be directed to the discovery of biomarkers that identify cases of endometriosis with oncogenic potential, the goal being to identify premalignant lesions and then study subsequent interventions in order to reduce the incidence of EAOCs and improve patient outcomes. Various technologies may be useful in the quest for biomarker discovery. Proteomic analysis by mass spectrometry of endometrial fluid from women with and without endometriosis has been used to putatively examine differential protein signatures between normal and gynaecologic disease conditions [126-128]. Circulating tumor DNA (ctDNA) can now be detected in blood and the presence of cancer-specific mutations may prove to be clinically useful for the diagnosis of both primary and recurrent disease, determining prognosis, and predicting treatment responses $[129,130]$. Thus, studying ctDNA could also play a role in the early detection of genomic dysregulation of cancer precursor lesions now known to be present in some patients with endometriosis [131]. In rare cases of atypical endometriosis not associated with cancer, biomarker research could theoretically identify those cases with true oncogenic potential. Future research efforts should also focus on establishing model systems of endometriosis (such as cell lines or xenografts). These studies could offer important insights into the risk factors, subtype-specific molecular traits, novel therapeutic testing, and the factors responsible for the development of EAOCs.

While we work with these new technologies to identify biomarkers of EAOC risk, it is important to highlight current interventions that are known to reduce the risk of ovarian cancer, including EnOC and CCC. Regular use of the oral contraceptive pill for 5 years results in a 20-30\% reduction in EnOC and CCC risk [132]. Similarly, tubal ligation is at least as effective as the oral contraceptive in reducing the risk of EAOCs, showing a reduction in EnOC and CCC risk of almost 50\% [133]. As the fallopian tube is the likely conduit for key factors resulting in the etiology and propagation of endometriosis, tubal occlusion is an important consideration for those women looking for permanent contraception. In these women, opportunistic salpingectomy also has the potential to reduce their risk of serous ovarian cancers and should be considered [134-137]. The latter strategy has been shown to be cost-effective [138-140].

Further research is needed to determine the role of risk-reducing bilateral salpingo-oophorectomy (BSO) to prevent EAOCs. One recent cost-effectiveness study suggests that BSO could be used in patients who have an overall lifetime risk of ovarian cancer higher than $4 \%$ [141]. In these cases, compliance with hormone replacement therapy must be high in order to mitigate the potential long-term adverse health effects of premature menopause [142].

\section{Conclusion}

For those women who are having surgery for endometriomas close to menopause, unilateral salpingo-oophorectomy may be considered if the endometrioma cannot be completely removed by cystectomy as most cases of EAOC arise from endometriomas. Finally, understanding the molecular biology of endometriosis will be the key to better treatments for endometriosis and guide future early detection and prevention strategies to further reduce the incidence and mortality of EAOCs.

\section{Conflicts of interest}

The authors have no conflicts of interest to declare.

\section{Acknowledgments}

Supporting research performed by the authors was funded in part through the Cararresi Foundation (OvCaRe Research Grant), the Canadian Institutes of Health Research (CIHR), the British Columbia Cancer Foundation (BCCF), and the VGH-UBC Hospital Foundation. 


\section{References}

1. Gynecologists ACoOa (2010) Management of endometriosis Clinical Management Guidelines of Obstetricians/Gynecologists 116(1) 223-236

2. Chapron C, Chopin N, and Borghese B, et al (2006) Deeply infiltrating endometriosis: pathogenetic implications of the anatomical distribution Hum Reprod 21(7) 1839-1845 https://doi.org/10.1093/humrep/del079 PMID: 16543256

3. Tosti C, Pinzauti S, and Santulli P, et al (2015) Pathogenetic mechanisms of deep infiltrating endometriosis Reprod Sci 22(9) 1053-1059 https://doi.org/10.1177/1933719115592713 PMID: 26169038

4. Darrow SL, Vena JE, and Batt RE, et al (1993) Menstrual cycle characteristics and the risk of endometriosis Epidemiology 4(2) 135-142 https://doi.org/10.1097/00001648-199303000-00009 PMID: 8452902

5. Signorello LB, Harlow BL, and Cramer DW, et al (1997) Epidemiologic determinants of endometriosis: a hospital-based casecontrol study Ann Epidemiol 7(4) 267-741 https://doi.org/10.1016/S1047-2797(97)00017-3 PMID: $\underline{9177109}$

6. Cramer DW and Missmer SA (2002) The epidemiology of endometriosis Ann N Y Acad Sci 955 11-22 https:// doi.org/10.1111/j.1749-6632.2002.tb02761.x PMID: 11949940

7. Candiani GB, Danesino V, and Gastaldi A, et al (1991) Reproductive and menstrual factors and risk of peritoneal and ovarian endometriosis Fertil Steril 56(2) 230-234 https://doi.org/10.1016/S0015-0282(16)54477-X PMID: 2070851

8. Kvaskoff M, Bijon A, and Clavel-Chapelon F, et al (2013) Childhood and adolescent exposures and the risk of endometriosis Epidemiology 24(2) 261-269 https://doi.org/10.1097/EDE.0b013e3182806445 PMID: 23337239

9. Matalliotakis IM, Arici A, and Cakmak H, et al (2008) Familial aggregation of endometriosis in the yale series Arch Gynecol Obstet 278(6) 507-511 https://doi.org/10.1007/s00404-008-0644-1 PMID: 18449556

10. Treloar SA, O'Connor DT, and O'Connor, et al (1999) Genetic influences on endometriosis in an Australian twin sample Fertil Steril 71(4) 701-710 https://doi.org/10.1016/S0015-0282(98)00540-8 PMID: 10202882

11. Rahmioglu N, Nyholt DR, and Morris AP, et al (2014) Genetic variants underlying risk of endometriosis: insights from metaanalysis of eight genome-wide association and replication datasets Hum Reprod Update 20(5) 702-716 https://doi.org/10.1093/ humupd/dmu015 PMID: 24676469 PMCID: $\underline{4132588}$

12. Nyholt DR, Low SK, and Anderson CA, et al (2012) Genome-wide association meta-analysis identifies new endometriosis risk loci Nat Genet 44(12) 1355-1359 https://doi.org/10.1038/ng.2445 PMID: $\underline{23104006}$ PMCID: 3527416

13. Jaaskelainen M, Prunskaite-Hyyrylainen R, and Naillat F, et al (2010) WNT4 is expressed in human fetal and adult ovaries and its signaling contributes to ovarian cell survival Mol Cell Endocrinol 317(1-2) 106-111 https://doi.org/10.1016/j.mce.2009.11.013

14. Vainio S, Heikkila M, and Kispert A, et al (1999) Female development in mammals is regulated by Wnt-4 signalling Nature 397(6718) 405-409 https://doi.org/10.1038/17068

15. Boyer A, Lapointe $E$, and Zheng X, et al (2010) WNT4 is required for normal ovarian follicle development and female fertility FASEB J 24(8) 3010-3025 https://doi.org/10.1096/fj.09-145789 PMID: 20371632 PMCID: 2909279

16. Guo X, Jing C, and Li L, et al (2011) Down-regulation of VEZT gene expression in human gastric cancer involves promoter methylation and miR-43c Biochem Biophys Res Commun 404(2) 622-627 https://doi.org/10.1016/j.bbrc.2010.12.026

17. Rae JM, Johnson MD, and Scheys JO, et al (2005) GREB 1 is a critical regulator of hormone dependent breast cancer growth Breast Cancer Res Treat 92(2) 141-149 https://doi.org/10.1007/s10549-005-1483-4 PMID: 15986123

18. Ghosh MG, Thompson DA, and Weigel RJ (2000) PDZK1 and GREB1 are estrogen-regulated genes expressed in hormoneresponsive breast cancer Cancer Res 60(22) 6367-6375 PMID: 11103799 
19. Albertsen HM, Chettier R, and Farrington $P$, et al (2013) Genome-wide association study link novel loci to endometriosis PLoS One 8(3) e58257 https://doi.org/10.1371/journal.pone.0058257 PMID: 23472165 PMCID: 3589333

20. Uno S, Zembutsu $\mathrm{H}$, and Hirasawa $\mathrm{A}$, et al (2010) A genome-wide association study identifies genetic variants in the CDKN2BAS locus associated with endometriosis in Japanese Nat Genet 42(8) 707-710 https://doi.org/10.1038/ng.612 PMID: 20601957

21. Painter JN, Anderson CA, and Nyholt DR, et al (2011) Genome-wide association study identifies a locus at $7 \mathrm{p} 15.2$ associated with endometriosis Nat Genet 43(1) 51-54 https://doi.org/10.1038/ng.731 PMCID: 3019124

22. Uimari O, Rahmioglu N, and Nyholt DR, et al (2017) Genome-wide genetic analyses highlight mitogen-activated protein kinase (MAPK) signaling in the pathogenesis of endometriosis Hum Reprod 32(4) 780-793 https://doi.org/10.1093/humrep/dex024 PMID: 28333195 PMCID: 5400041

23. Sapkota $\mathrm{Y}$, Steinthorsdottir $\mathrm{V}$, and Morris AP, et al (2017) Meta-analysis identifies five novel loci associated with endometriosis highlighting key genes involved in hormone metabolism Nat Commun 815539 https://doi.org/10.1038/ncomms15539 PMID: $\underline{28537267}$ PMCID: $\underline{5458088}$

24. Fung JN, Rogers PA, and Montgomery GW (2015) Identifying the biological basis of GWAS hits for endometriosis Biol Reprod 92(4) 87 https://doi.org/10.1095/biolreprod.114.126458 PMID: 25695719

25. Sampson JA (1927) Peritoneal endometriosis due to the menstrual dissemination of endometrial tissue into the peritoneal cavity Am J Obstet Gynecol 14 422-469 https://doi.org/10.1016/S0002-9378(15)30003-X

26. Ferguson BR, Bennington JL, and Haber SL (1969) Histochemistry of mucosubstances and histology of mixed mullerian pelvic lymph node glandular inclusions. evidence for histogenesis by mullerian metaplasia of coelomic epithelium Obstet Gynecol 33(5) 617-625 PMID: $\underline{5778441}$

27. Sampson JA (1927) Metastatic or embolic endometriosis, due to the menstrual dissemination of endometrial tissue into the venous circulation Am J Pathol 3(2) 93-110 PMID: 19969738 PMCID: 1931779

28. Lagana AS, Vitale SG, and Salmeri FM, et al (2017) Unus pro omnibus, omnes pro uno: a novel, evidence-based, unifying theory for the pathogenesis of endometriosis Med Hypotheses 103 10-20 https://doi.org/10.1016/j.mehy.2017.03.032 PMID: 28571791

29. Rodrigues MC, Lippert T, and Nguyen $\mathrm{H}$, et al (2016) Menstrual blood-derived stem cells: in vitro and in vivo characterization of functional effects Adv Exp Med Biol 951 111-121 https://doi.org/10.1007/978-3-319-45457-3 9 PMID: 27837558

30. Anglesio MS, Papadopoulos N, and Ayhan A, et al (2017) Cancer-associated mutations in endometriosis without cancer N Engl J Med 376(19) 1835-1848 https://doi.org/10.1056/NEJMoa1614814 PMID: 28489996 PMCID: $\underline{5555376}$

31. Hidalgo $M$, Amant $F$, and Biankin $A V$, et al (2014) Patient-derived xenograft models: an emerging platform for translational cancer research Cancer Discov 4(9) 998-1013 https://doi.org/10.1158/2159-8290.CD-14-0001 PMID: 25185190 PMCID: $\underline{4167608}$

32. Schneeberger VE, Allaj V, and Gardner EE, et al (2016) Quantitation of murine stroma and selective purification of the human tumor component of patient-derived xenografts for genomic analysis PLoS One 11(9) e0160587 https://doi.org/10.1371/journal. pone. 0160587 PMID: 27611664 PMCID: 5017757

33. Zhao L, Gu C, and Ye M, et al (2017) Identification of global transcriptome abnormalities and potential biomarkers in eutopic endometria of women with endometriosis: a preliminary study Biomed Rep 6(6) 654-662 https://doi.org/10.3892/br.2017.902 PMID: 28584637 PMCID: 5449958

34. Jansen M and Wright N (2016) Advances in Experimental Medicine and Biology Series. Stem Cells, Pre-neoplasia and Early Cancer of the Upper Gastrointestinal Tract (Switzerland: Springer) Vol 908 p 486

35. Evans JA and McDonald SA (2016) The complex, clonal, and controversial nature of barrett's esophagus Adv Exp Med Bio/ 908, 27-40 https://doi.org/10.1007/978-3-319-41388-4_3 PMID: 27573766 
36. Garman KS (2017) Origin of barrett's epithelium: esophageal submucosal glands Cell Mol Gastroenterol Hepatol 4(1) 153-156 https://doi.org/10.1016/j.jcmgh.2017.01.016 PMID: 28593186 PMCID: $\underline{5453879}$

37. Lorinc E and Oberg S (2012) Submucosal glands in the columnar-lined oesophagus: evidence of an association with metaplasia and neosquamous epithelium Histopathology 61(1) 53-58 https://doi.org/10.1111/j.1365-2559.2012.04180.x PMID: 22458702

38. Lorinc E and Oberg S (2015) Hyperplasia of the submucosal glands of the columnar-lined oesophagus Histopathology 66(5) 726-731 https://doi.org/10.1111/his.12604

39. Wang DH and Souza RF (2016) Transcommitment: paving the way to barrett's Metaplasia Adv Exp Med Bio/ 908 183-212 https:// doi.org/10.1007/978-3-319-41388-4_10 PMID: 27573773

40. Vercellini P, Parazzini F, and Bolis G, et al (1993) Endometriosis and ovarian cancer Am J Obstet Gynecol 169(1) 181-182 https:// doi.org/10.1016/0002-9378(93)90159-G PMID: 8392791

41. Jimbo H, Yoshikawa $\mathrm{H}$, and Onda T, et al (1997) Prevalence of ovarian endometriosis in epithelial ovarian cancer Int J Gynaecol Obstet 59(3) 245-250 https://doi.org/10.1016/S0020-7292(97)00238-5

42. Stamp JP, Gilks CB, and Wesseling M, et al (2016) BAF250a expression in atypical endometriosis and endometriosis-associated ovarian cancer Int J Gynecol Cancer 26(5) 825-832 https://doi.org/10.1097/IGC.0000000000000698 PMID: 27051059

43. LaGrenade A and Silverberg SG (1988) Ovarian tumors associated with atypical endometriosis Hum Pathol 19(9) 1080-1084 https://doi.org/10.1016/S0046-8177(88)80090-X PMID: $\underline{3417292}$

44. Fukunaga M, Nomura K, and Ishikawa E, et al (1997) Ovarian atypical endometriosis: its close association with malignant epithelial tumours Histopathology 30(3) 249-255 https://doi.org/10.1046/j.1365-2559.1997.d01-592.x PMID: 9088954

45. Bedaiwy MA, Hussein MR, and Biscotti C, et al (2009) Pelvic endometriosis is rarely associated with ovarian borderline tumours, cytologic and architectural atypia: a clinicopathologic study Pathol Oncol Res 15(1) 81-88 https://doi.org/10.1007/s12253-008$\underline{9072-6}$

46. Wei JJ, William J, and Bulun S (2011) Endometriosis and ovarian cancer: a review of clinical, pathologic, and molecular aspects Int J Gynecol Pathol 30(6) 553-568 https://doi.org/10.1097/PGP.0b013e31821f4b85 PMID: 21979592 PMCID: 4130217

47. Maeda D and Shih le M (2013) Pathogenesis and the role of ARID1A mutation in endometriosis-related ovarian neoplasms Adv Anat Pathol 20(1) 45-52 https://doi.org/10.1097/PAP.0b013e31827bc24d

48. Samartzis EP, Noske A, and Dedes KJ, et al (2013) ARID1A mutations and PI3K/AKT pathway alterations in endometriosis and endometriosis-associated ovarian carcinomas Int J Mol Sci 14(9) 18824-18849 https://doi.org/10.3390/iims140918824 PMID: 24036443 PMCID: $\underline{3794809}$

49. Pearce CL, Templeman C, and Rossing MA, et al (2012) Association between endometriosis and risk of histological subtypes of ovarian cancer: a pooled analysis of case-control studies Lancet Oncol 13(4) 385-394 https://doi.org/10.1016/S14702045(11)70404-1 PMID: 22361336 PMCID: $\underline{3664011}$

50. Kondi-Pafiti A, Spanidou-Carvouni $\mathrm{H}$, and Papadias K, et al (2004) Malignant neoplasms arising in endometriosis: clinicopathological study of 14 cases Clin Exp Obstet Gynecol 31(4) 302-304

51. Yang C, Oh HK, and Kim D (2014) Mullerian adenosarcoma arising from rectal endometriosis Ann Coloproctol 30(5) 232-236 https://doi.org/10.3393/ac.2014.30.5.232 PMID: 25360431 PMCID: $\underline{4213940}$

52. Masand RP, Euscher ED, and Deavers MT, et al (2013) Endometrioid stromal sarcoma: a clinicopathologic study of 63 cases $\mathrm{Am}$ J Surg Pathol 37(11) 1635-1647 https://doi.org/10.1097/PAS.0000000000000083 PMID: 24121169

53. Pearce CL, Stram DO, and Ness RB, et al (2015) Population distribution of lifetime risk of ovarian cancer in the United States Cancer Epidemiol Biomarkers Prev 24(4) 671-676 https://doi.org/10.1158/1055-9965.EPI-14-1128 PMID: 25623732 PMCID: 4892114 
54. Anglesio MS, Bashashati A, and Wang YK, et al (2015) Multifocal endometriotic lesions associated with cancer are clonal and carry a high mutation burden J Pathol 236(2) 201-209 https://doi.org/10.1002/path.4516 PMID: 25692284

55. Yu HC, Lin CY, and Chang WC, et al (2015) Increased association between endometriosis and endometrial cancer: a nationwide population-based retrospective cohort study Int J Gynecol Cancer 25(3) 447-452 https://doi.org/10.1097//GC.0000000000000384 PMID: 25695548 PMCID: $\underline{4340602}$

56. Anglesio MS, Carey MS, and Kobel M, et al (2011) Clear cell carcinoma of the ovary: a report from the first Ovarian Clear Cell Symposium, June 24th, 2010 Gynecol Oncol 121(2) 407-415 https://doi.org/10.1016/..ygyno.2011.01.005 PMID: 21276610

57. Wiegand KC, Shah SP, and Al-Agha OM, et al (2010) ARID1A mutations in endometriosis-associated ovarian carcinomas N Engl J Med 363(16) 1532-1543 https://doi.org/10.1056/NEJMoa1008433 PMID: 20942669 PMCID: 2976679

58. Berker B and Seval M (2015) Problems with the diagnosis of endometriosis Womens Health (Lond) 11(5) 597-601 https://doi. org/10.2217/whe.15.44

59. Moss EL, Hollingworth J, and Reynolds TM (2005) The role of CA125 in clinical practice J Clin Pathol 58(3) 308-312 https://doi. org/10.1136/jcp.2004.018077 PMID: 15735166 PMCID: 1770590

60. Huhtinen K, Suvitie P, and Hiissa J, et al (2009) Serum HE4 concentration differentiates malignant ovarian tumours from ovarian endometriotic cysts Br J Cancer 100(8) 1315-1319 https://doi.org/10.1038/sj.bjc.6605011 PMID: 19337252 PMCID: 2676558

61. Leyland N, Casper R, and Laberge P, et al (2010) Endometriosis: diagnosis and management $J$ Obstet Gynaecol Can 32(7 Suppl 2) S1-32 https://doi.org/10.1016/S1701-2163(16)34589-3

62. Wykes CB, Clark TJ, and Khan KS (2004) Accuracy of laparoscopy in the diagnosis of endometriosis: a systematic quantitative review BJOG 111(11) 1204-1212 https://doi.org/10.1111/j.1471-0528.2004.00433.x PMID: 15521864

63. Hori Y and Committee SG (2008) Diagnostic laparoscopy guidelines : this guideline was prepared by the SAGES guidelines committee and reviewed and approved by the Board of Governors of the society of American gastrointestinal and endoscopic surgeons (SAGES), November 2007 Surg Endosc 22(5) 1353-1383 https://doi.org/10.1007/s00464-008-9759-5 PMID: 18389320

64. Burney RO and Giudice LC (2012) Pathogenesis and pathophysiology of endometriosis Fertil Steril 98(3) 511-519 https://doi. org/10.1016/j.fertnstert.2012.06.029 PMID: 22819144 PMCID: $\underline{3836682}$

65. Eskenazi B and Warner ML (1997) Epidemiology of endometriosis Obstet Gynecol Clin North Am 24(2) 235-258 https://doi. org/10.1016/S0889-8545(05)70302-8 PMID: $\underline{9163765}$

66. Rogers PA, D'Hooghe TM, and Fazleabas A, et al (2013) Defining future directions for endometriosis research: workshop report from the 2011 World Congress of Endometriosis in Montpellier, France Reprod Sci 20(5) 483-499 https://doi. org/10.1177/1933719113477495 PMID: 23427182 PMCID: $\underline{3635070}$

67. Burghaus S, Haberle L,and Schrauder MG, et al (2015) Endometriosis as a risk factor for ovarian or endometrial cancer - results of a hospital-based case-control study BMC Cancer $15751 \mathrm{https}: / /$ doi.org/10.1186/s12885-015-1821-9

68. Wykes CB, Clark TJ, and Chakravati S, et al (2006) Efficacy of laparoscopic excision of visually diagnosed peritoneal endometriosis in the treatment of chronic pelvic pain Eur J Obstet Gynecol Reprod Biol 125(1) 129-133 https://doi.org/10.1016/j. ejogrb.2005.08.008

69. Bedaiwy MA, Alfaraj S, and Yong P, et al (2017) New developments in the medical treatment of endometriosis Fertil Steril 107(3) 555-565 https://doi.org/10.1016/j.fertnstert.2016.12.025 PMID: 28139238

70. Streuli I, de Ziegler D, and Borghese B, et al (2012) New treatment strategies and emerging drugs in endometriosis Expert Opin Emerg Drugs 17(1) 83-104 https://doi.org/10.1517/14728214.2012.668885 PMID: 22439891 
71. Streuli I, de Ziegler D, and Santulli, et al (2013) An update on the pharmacological management of endometriosis Expert Opin Pharmacother 14(3) 291-305 https://doi.org/10.1517/14656566.2013.767334 PMID: 23356536

72. Giudice LC and Kao LC (2004) Endometriosis Lancet 364(9447) 1789-1799 https://doi.org/10.1016/S0140-6736(04)17403-5 PMID: 15541453

73. Kobayashi H (2009) Ovarian cancer in endometriosis: epidemiology, natural history, and clinical diagnosis Int J Clin Oncol 14(5) 378-382 https://doi.org/10.1007/s10147-009-0931-2 PMID: 19856043

74. Bukulmez O, Hardy DB, and Carr BR, et al (2008) Inflammatory status influences aromatase and steroid receptor expression in endometriosis Endocrinology 149(3) 1190-1204 https://doi.org/10.1210/en.2007-0665

75. Han SJ and O'Malley BW (2014) The dynamics of nuclear receptors and nuclear receptor coregulators in the pathogenesis of endometriosis Hum Reprod Update 20(4) 467-484 https://doi.org/10.1093/humupd/dmu002 PMID: 24634322 PMCID: 4063700

76. Guo SW (2009) Epigenetics of endometriosis Mol Hum Reprod 15(10) 587-607 https://doi.org/10.1093/molehr/gap064 PMID: 19651637

77. Kobayashi H, Imanaka S, and Nakamura $\mathrm{H}$, et al (2014) Understanding the role of epigenomic, genomic and genetic alterations in the development of endometriosis (review) Mol Med Rep 9(5) 1483-1505 https://doi.org/10.3892/mmr.2014.2057 PMID: 24639062

78. Kobayashi H, Yamada Y, and Kanayama S, et al (2009) The role of iron in the pathogenesis of endometriosis Gynecol Endocrinol 25(1) 39-52 https://doi.org/10.1080/09513590802366204 PMID: 19165662

79. Vercellini P, Crosignani P, and Somigliana E, et al (2011) The 'incessant menstruation' hypothesis: a mechanistic ovarian cancer model with implications for prevention Hum Reprod 26(9) 2262-2273 https://doi.org/10.1093/humrep/der211 PMID: 21724568

80. Toyokuni S (2009) Role of iron in carcinogenesis: cancer as a ferrotoxic disease Cancer Sci 100(1) 9-16 https://doi.org/10.1111/ j.1349-7006.2008.01001.x

81. Ota $\mathrm{H}$, Igarashi $\mathrm{S}$, and Sasaki M, et al (2001) Distribution of cyclooxygenase-2 in eutopic and ectopic endometrium in endometriosis and adenomyosis Hum Reprod 16(3) 561-566 https://doi.org/10.1093/humrep/16.3.561 PMID: 11228229

82. Lin YJ, Lai MD, and Lei HY, et al (2006) Neutrophils and macrophages promote angiogenesis in the early stage of endometriosis in a mouse model Endocrinology 147(3) 1278-1286 https://doi.org/10.1210/en.2005-0790

83. Ahn SH, Edwards AK, and Singh SS, et al (2015) IL-17A contributes to the pathogenesis of endometriosis by triggering proinflammatory cytokines and angiogenic growth factors $\mathrm{J} / \mathrm{mmuno} / 195(6)$ 2591-2600 https://doi.org/10.4049/jimmunol.1501138 PMID: 26259585 PMCID: $\underline{4561197}$

84. Zhang $\mathrm{X}, \mathrm{Xu} \mathrm{H}$, and Lin J, et al (2005) Peritoneal fluid concentrations of interleukin-17 correlate with the severity of endometriosis and infertility of this disorder BJOG 112(8) 1153-1155 https://doi.org/10.1111/j.1471-0528.2005.00639.x PMID: 16045534

85. McKinnon BD, Bertschi D, and Bersinger NA, et al (2015) Inflammation and nerve fiber interaction in endometriotic pain Trends Endocrinol Metab 26(1) 1-10 https://doi.org/10.1016/j.tem.2014.10.003

86. Worley MJ, Welch WR, and Berkowitz RS, et al (2013) Endometriosis-associated ovarian cancer: a review of pathogenesis Int J Mol Sci 14(3) 5367-5379 https://doi.org/10.3390/ijms14035367 PMID: 23466883 PMCID: 3634491

87. Jiang X, Morland SJ, and Hitchcock A, et al (1998) Allelotyping of endometriosis with adjacent ovarian carcinoma reveals evidence of a common lineage Cancer Res 58(8) 1707-1712 PMID: 9563487

88. Scott RB (1953) Malignant changes in endometriosis Obstet Gynecol 2(3) 283-289 PMID: 13087921

89. Lu Y, Cuellar-Partida G, and Painter JN, et al (2015) Shared genetics underlying epidemiological association between endometriosis and ovarian cancer Hum Mol Genet 24(20) 5955-5964 https://doi.org/10.1093/hmg/ddv306 PMID: 26231222 PMCID: 4581608 
90. Prowse AH, Manek S, and Varma R, et al (2006) Molecular genetic evidence that endometriosis is a precursor of ovarian cancer Int J Cancer 119(3) 556-562 https://doi.org/10.1002/ijc.21845 PMID: 16506222

91. McMeekin DS, Burger RA, and Manetta A, et al (1995) Endometrioid adenocarcinoma of the ovary and its relationship to endometriosis Gynecol Oncol 59(1) 81-86 https://doi.org/10.1006/gyno.1995.1271 PMID: 7557621

92. Sainz de la Cuesta R, Eichhorn JH, and Rice LW, et al (1996) Histologic transformation of benign endometriosis to early epithelial ovarian cancer Gynecol Oncol 60(2) 238-244 https://doi.org/10.1006/gyno.1996.0032 PMID: 8631545

93. Worley MJ, Jr., Liu S, and Hua Y, et al (2015) Molecular changes in endometriosis-associated ovarian clear cell carcinoma Eur J Cancer 51(13) 1831-1842 https://doi.org/10.1016/j.ejca.2015.05.011 PMID: 26059197 PMCID: 4532605

94. Sato N, Tsunoda H, and Nishida M, et al (2000) Loss of heterozygosity on 10q23.3 and mutation of the tumor suppressor gene PTEN in benign endometrial cyst of the ovary: possible sequence progression from benign endometrial cyst to endometrioid carcinoma and clear cell carcinoma of the ovary Cancer Res 60(24) 7052-7056

95. Chene G, Ouellet V, and Rahimi K, et al (2015) The ARID1A pathway in ovarian clear cell and endometrioid carcinoma, contiguous endometriosis, and benign endometriosis Int J Gynaecol Obstet 130(1) 27-30 https://doi.org/10.1016/j.ijgo.2015.02.021 PMID: 25912412

96. Bischoff FZ, Heard M, and Simpson JL (2002) Somatic DNA alterations in endometriosis: high frequency of chromosome 17 and p53 loss in late-stage endometriosis J Reprod Immunol 55(1-2) 49-64 https://doi.org/10.1016/S0165-0378(01)00131-0 PMID: 12062821

97. Sainz de la Cuesta R, Izquierdo M, and Canamero M, et al (2004) Increased prevalence of p53 overexpression from typical endometriosis to atypical endometriosis and ovarian cancer associated with endometriosis Eur J Obstet Gynecol Reprod Biol 113(1) 87-93 https://doi.org/10.1016/S0301-2115(03)00367-1 PMID: 15036718

98. Vestergaard AL, Thorup K, and Knudsen UB, et al (2011) Oncogenic events associated with endometrial and ovarian cancers are rare in endometriosis Mol Hum Reprod 17(12) 758-761 https://doi.org/10.1093/molehr/gar049 PMID: 21724579

99. Laudanski P, Szamatowicz J, and Kowalczuk O, et al (2009) Expression of selected tumor suppressor and oncogenes in endometrium of women with endometriosis Hum Reprod 24(8) 1880-1890 https://doi.org/10.1093/humrep/dep175 PMID: 19429661

100. Yamamoto S, Tsuda H, and Takano M, et al (2011) PIK3CA mutation is an early event in the development of endometriosisassociated ovarian clear cell adenocarcinoma J Pathol 225(2) 189-194 https://doi.org/10.1002/path.2940 PMID: 21735444

101. Grassi T, Calcagno,A, and Marzinotto S, et al (2015) Mismatch repair system in endometriotic tissue and eutopic endometrium of unaffected women Int J Clin Exp Pathol 8(2) 1867-1877 PMID: 25973079 PMCID: 4396318

102. Fuseya C, Horiuchi A, and Hayashi A, et al (2012) Involvement of pelvic inflammation-related mismatch repair abnormalities and microsatellite instability in the malignant transformation of ovarian endometriosis Hum Pathol 43(11) 1964-1972 https://doi. org/10.1016/j.humpath.2012.02.005 PMID: 22626277

103. Yang $\mathrm{W}$, Zhang $\mathrm{Y}$, and $\mathrm{Fu} F$, et al (2013) High-resolution array-comparative genomic hybridization profiling reveals $20 \mathrm{q} 13.33$ alterations associated with ovarian endometriosis Gynecol Endocrinol 29(6) 603-607 https://doi.org/10.3109/09513590.2013.788 $\underline{632}$ PMID: 23656391

104.Mafra F, Mazzotti D, and Pellegrino R, et al (2016) Copy number variation analysis reveals additional variants contributing to endometriosis development $J$ Assist Reprod Genet 34(1) 117-124 https://doi.org/10.1007/s10815-016-0822-1 PMID: 27817035 PMCID: 5330977

105. Ali-Fehmi R, Khalifeh I, and Bandyopadhyay S, et al (2006) Patterns of loss of heterozygosity at 10q23.3 and microsatellite instability in endometriosis, atypical endometriosis, and ovarian carcinoma arising in association with endometriosis Int $\mathrm{J} \mathrm{Gynecol}$ Pathol 25(3) 223-229 https://doi.org/10.1097/01.pgp.0000192274.44061.36 PMID: 16810057 
106.Xu B, Hamada S, and Kusuki I, et al (2011) Possible involvement of loss of heterozygosity in malignant transformation of ovarian endometriosis Gynecol Oncol 120(2) 239-246 https://doi.org/10.1016/j.ygyno.2010.10.036

107. Obata K and Hoshiai H (2000) Common genetic changes between endometriosis and ovarian cancer Gynecol Obstet Invest 50(Suppl 1) 39-43 https://doi.org/10.1159/000052877 PMID: 11093060

108. Thomas EJ and Campbell IG (2000) Molecular genetic defects in endometriosis Gynecol Obstet Invest 50 (Suppl 1) $44-50$ https:/l doi.org/10.1159/000052878 PMID: 11093061

109. Jiang X, Hitchcock A, and Bryan EJ, et al (1996) Microsatellite analysis of endometriosis reveals loss of heterozygosity at candidate ovarian tumor suppressor gene loci Cancer Res 56(15) 3534-3539 PMID: 8758923

110. Silveira CG, Abrao MS, and Dias JA, Jr., et al (2012) Common chromosomal imbalances and stemness-related protein expression markers in endometriotic lesions from different anatomical sites: the potential role of stem cells Hum Reprod 27(11) 3187-3197 https://doi.org/10.1093/humrep/des282 PMID: 22940770

111. Kapoor H, Agrawal DK, and Mittal SK (2015) Barrett's esophagus: recent insights into pathogenesis and cellular ontogeny Trans/ Res 166(1) 28-40 https://doi.org/10.1016/j.trsl.2015.01.009 PMID: 25701368

112. Suryawanshi S, Huang X, and Elishaev E, et al (2014) Complement pathway is frequently altered in endometriosis and endometriosis-associated ovarian cancer Clin Cancer Res 20(23) 6163-6174 https://doi.org/10.1158/1078-0432.CCR-14-1338 PMID: 25294912 PMCID: $\underline{4252715}$

113. Rutkowski MJ, Sughrue ME, and Kane AJ, et al (2010) Cancer and the complement cascade Mol Cancer Res 8(11) 1453-1465 https://doi.org/10.1158/1541-7786.MCR-10-0225 PMID: 20870736

114. Edwards RP, Huang X, and Vlad AM (2015) Chronic inflammation in endometriosis and endometriosis-associated ovarian cancer: New roles for the "old" complement pathway Oncoimmunology 4(5) e1002732 https://doi.org/10.1080/2162402X.2014.1002732 PMID: 26155393 PMCID: $\underline{4485759}$

115. Lee AW, Templeman C, and Stram DA, et al (2015) Evidence of a genetic link between endometriosis and ovarian cancer Fertil Steril 105(1) 35-43 https://doi.org/10.1016/j.fertnstert.2015.09.023 PMID: 26477498 PMCID: 5068352

116. Yamamoto S, Tsuda H, and Takano M, et al (2012) Loss of ARID1A protein expression occurs as an early event in ovarian clearcell carcinoma development and frequently coexists with PIK3CA mutations Mod Pathol 25(4) 615-624 https://doi.org/10.1038/ modpathol.2011.189

117. Wu RC, Wang TL, and Shih le M (2014) The emerging roles of ARID1A in tumor suppression Cancer Biol Ther 15(6) 655-664 https://doi.org/10.4161/cbt.28411 PMID: 24618703 PMCID: 4049780

118. Nishikimi K, Kiyokawa T, andTate S, et al (2015) ARID1A expression in ovarian clear cell carcinoma with an adenofibromatous component Histopathology 67(6) 866-871 https://doi.org/10.1111/his.12721 PMID: 25913291

119. Guan B, Rahmanto YS, and Wu RC, et al (2014) Roles of deletion of Arid1a, a tumor suppressor, in mouse ovarian tumorigenesis J Natl Cancer Inst 106(7) dju146 https://doi.org/10.1093/inci/dju146 PMID: 24899687 PMCID: 4056776

120. Borrelli GM, Abrao MS, and Taube ET, et al (2016) (Partial) Loss of BAF250a (ARID1A) in rectovaginal deep-infiltrating endometriosis, endometriomas and involved pelvic sentinel lymph nodes Mol Hum Reprod 22(5) 329-337 https://doi.org/10.1093/ molehr/gaw009 PMID: $\underline{26832958}$

121. Tomasetti $C$ and Vogelstein $B$ (2015) Cancer etiology. variation in cancer risk among tissues can be explained by the number of stem cell divisions Science 347(6217) 78-81 https://doi.org/10.1126/science.1260825 PMID: 25554788 PMCID: 4446723

122. Katagiri A, Nakayama K, and Rahman MT, et al (2012) Loss of ARID1A expression is related to shorter progression-free survival and chemoresistance in ovarian clear cell carcinoma Mod Pathol 25(2) 282-288 
123. Lowery WJ, Schildkraut JM, and Akushevich L, et al (2012) Loss of ARID1A-associated protein expression is a frequent event in clear cell and endometrioid ovarian cancers Int J Gynecol Cancer 22(1) 9-14 https://doi.org/10.1097/IGC.0b013e318231f140 PMCID: $\underline{3263359}$

124.Wiegand KC, Hennessy BT, and Leung S, et al (2014) A functional proteogenomic analysis of endometrioid and clear cell carcinomas using reverse phase protein array and mutation analysis: protein expression is histotype-specific and loss of ARID1A/BAF250a is associated with AKT phosphorylation BMC Cancer 14120 https://doi.org/10.1186/1471-2407-14-120 PMID: 24559118 PMCID: $\underline{3941949}$

125. Minlikeeva AN, Freudenheim JL, and Eng, KH, et al (2017) History of comorbidities and survival of ovarian cancer patients, results from the ovarian cancer association consortium Cancer Epidemiol Biomarkers Prev 26(9) 1470-1473 https://doi. org/10.1158/1055-9965.EPI-17-0367 PMID: 28864456 PMCID: $\underline{5649363}$

126. Ametzazurra A, Matorras R, and Garcia-Velasco JA, et al (2009) Endometrial fluid is a specific and non-invasive biological sample for protein biomarker identification in endometriosis Hum Reprod 24(4) 954-965 https://doi.org/10.1093/humrep/den450

127. Casado-Vela J, Rodriguez-Suarez E, and Iloro I, et al (2009) Comprehensive proteomic analysis of human endometrial fluid aspirate J Proteome Res 8(10) 4622-4632 https://doi.org/10.1021/pr9004426 PMID: 19670903

128. Yang H, Lau WB, and Lau B, et al (2015) A mass spectrometric insight into the origins of benign gynecological disorders Mass Spectrom Rev 36(3) 450-470 https://doi.org/10.1002/mas.21484 PMID: 26633258

129.Di Meo A, Bartlett J, and Cheng Y, et al (2017) Liquid biopsy: a step forward towards precision medicine in urologic malignancies Mol Cancer 16(1) 80 https://doi.org/10.1186/s12943-017-0644-5 PMID: 28410618 PMCID: 5391592

130.Perakis, S and Speicher, MR (2017) Emerging concepts in liquid biopsies BMC Med 15(1) 75 https://doi.org/10.1186/s12916-0170840-6 PMID: 28381299 PMCID: $\underline{5382440}$

131. Offin M, Chabon JJ, and Razavi P, et al (2017) Capturing genomic evolution of lung cancers through liquid biopsy for circulating tumor DNA J Oncol 20174517834 https://doi.org/10.1155/2017/4517834 PMID: 28392802 PMCID: 5368362

132. Collaborative Group on Epidemiological Studies of Ovarian C, Beral V, and Doll R, et al (2008) Ovarian cancer and oral contraceptives: collaborative reanalysis of data from 45 epidemiological studies including 23,257 women with ovarian cancer and 87,303 controls Lancet 371(9609) 303-314 https://doi.org/10.1016/S0140-6736(08)60167-1

133. Gaitskell K, Green J, and Pirie K, et al (2016) Tubal ligation and ovarian cancer risk in a large cohort: Substantial variation by histological type Int J Cancer 138(5) 1076-1084 https://doi.org/10.1002/ijc.29856 PMCID: 4832307

134. Chene G, de Rochambeau B, and Le Bail-Carval K, et al (2016) Current surgical practice of prophylactic and opportunistic salpingectomy in France Gynecol Obstet Fertil 44(7-8) 377-384 https://doi.org/10.1016/j.gyobfe.2016.05.003 PMID: 27363615

135. Chene G, Caloone J, and Moret S, et al (2016) Is endometriosis a precancerous lesion? Perspectives and clinical implications Gynecol Obstet Fertil 44(2) 106-112 https://doi.org/10.1016/j.gyobfe.2016.01.001 PMID: 26850282

136. Cibula D, Widschwendter M, and Majek O, et al (2011) Tubal ligation and the risk of ovarian cancer: review and meta-analysis Hum Reprod Update 17(1) 55-67 https://doi.org/10.1093/humupd/dmq030

137. Kwon JS (2015) Ovarian cancer risk reduction through opportunistic salpingectomy J Gynecol Oncol 26(2) 83-86 https://doi. org/10.3802/jgo.2015.26.2.83 PMID: 25872888 PMCID: $\underline{4397236}$

138. Tai RWM, Choi SKY, and Coyte PC (2017) The cost-effectiveness of salpingectomies for family planning in the prevention of ovarian cancer J Obstet Gynaecol Can S1701-S2163(17) 30493-30500

139. Dilley SE, Havrilesky LJ, and Bakkum-Gamez J, et al (2017) Cost-effectiveness of opportunistic salpingectomy for ovarian cancer prevention Gynecol Oncol 146(2) 373-379 https://doi.org/10.1016/j.ygyno.2017.05.034 PMID: 28577884 
140.Kwon JS, McAlpine JN, and Hanley GE, et al (2015) Costs and benefits of opportunistic salpingectomy as an ovarian cancer prevention strategy Obstet Gynecol 125(2) 338-345 https://doi.org/10.1097/AOG.0000000000000630 PMID: 25568991

141. Manchanda R, Legood R, and Antoniou AC, et al (2016) Specifying the ovarian cancer risk threshold of 'premenopausal riskreducing salpingo-oophorectomy' for ovarian cancer prevention: a cost-effectiveness analysis J Med Genet 53(9) 591-599 https://doi.org/10.1136/jmedgenet-2016-103800 PMID: 27354448

142. Parker WH, Feskanich D, and Broder MS, et al (2013) Long-term mortality associated with oophorectomy compared with ovarian conservation in the nurses' health study Obstet Gynecol 121(4) 709-716 https://doi.org/10.1097/AOG.0b013e3182864350 PMID: 23635669 PMCID: $\underline{4254662}$ 